\title{
Hot Rolling Mill Hydraulic Gap Control (HGC) thickness control improvement
}

\author{
Peter Kucsera*, Zsolt Béres** \\ * Óbuda University, Tavaszmező u. 15-17, H-1084 Budapest, Hungary \\ kucsera.pete@kvk.uni-obuda.hu \\ **Alcoa-Köfém Kft., Verseci u. 1-15, H-8000 Székesfehérvár, Hungary, \\ zsolt.beres@alcoa.com
}

Abstract: In this article the AGC (Automated Gauge Control) system, of a hot rolling mill is analyzed and different methods are described to improve its performance. The mill stretch compensation and other disturbances during the rolling process are compensated and a rolling speed dependent, adaptive PI controller is developed to accomplish fine thickness control. The improved system has been validated by measurements. Future improvement options are also analyzed, like eccentricity compensation, and predictive control of thickness.

Keywords: Hot rolling mill; AGC; Automatic Gauge Control; HGC; Hydraulic Gap Control; Mill stretch compensation; Roll eccentricity compensation; Thickness control; Adaptive; Predictive control

\section{Introduction}

Nowadays, the competitive nature of different sectors (industry, agriculture, ...) depends on technological improvements [1]. There is a growing demand for high accuracy in thickness control in metal rolling area. If the required accuracy of hot rolling mills can be achieved, then in some cases, cold rolling is not even required, which can result in a radical decrease of production costs.

The schematic structure of a typical aluminum hot reversing rolling mill can be seen in Figure 1. The aluminum slabs, which have to be rolled, are transported from a re-heat furnace via a roller table, then heated to around $420-450{ }^{\circ} \mathrm{C}$. The initial slab thickness is around $500 \mathrm{~mm}$. The target thickness is typically 5 to 10 millimeters, and then the product is coiled. To reach this thickness, the strip has to be rolled several times on a reversing mill. Rolling is done by two work rolls, each supported by backup rolls. The maximum rolling force can reach 3-40000 kN. Typically, the roll gap is determined by set point of the main screws, located on both sides of the mill stand. The screws provide only a rough positioning without 
load between passes, and for accurate positioning during rolling two hydraulic cylinders are installed. The position of the cylinders is controlled by servo valves and the corresponding position controllers. This hydraulic servo is often called HGC (Hydraulic Gap Control) cylinder. The AGC system provides the reference value for the HGC positioning system.

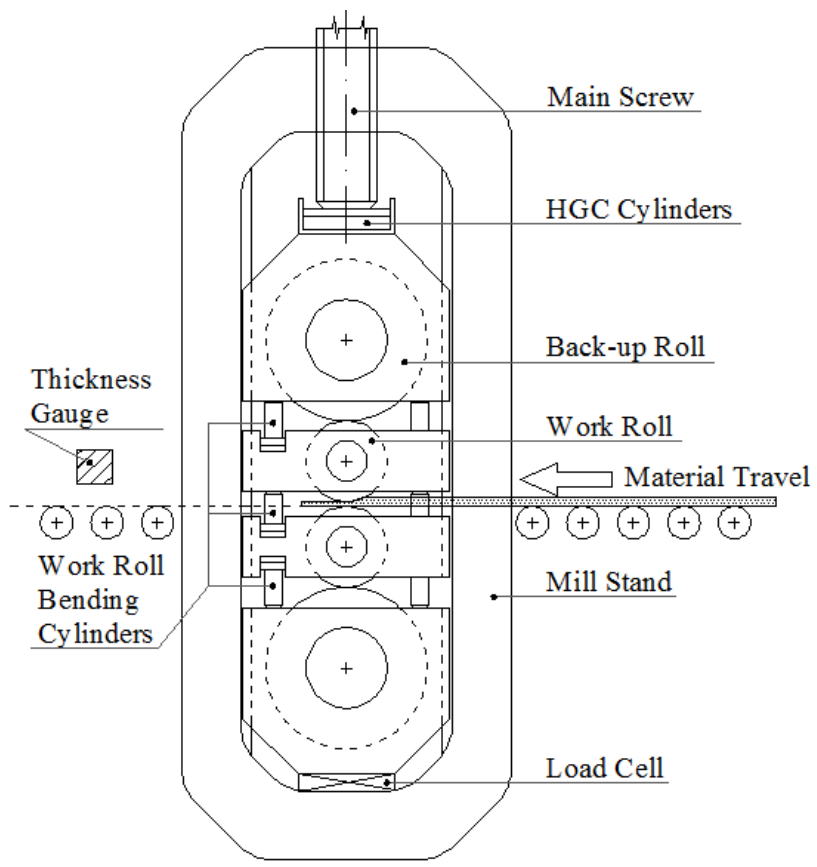

Figure 1

Schematic structure of a hot rolling mill

The thickness of the rolled material is measured by an X-Ray thickness gauge in the last pass. This measurement is possible within several meters distance from the roll gap, therefore considerable dead time has to be taken into account in thickness control.

The rolling force can be measured by a load cell or can be calculated from the pressure of the HGC cylinders. Due to several reasons (deflection of the rolls caused by the rolling force, the thermal crown and the ground crown), the roll gap is not uniform across the sheet, and therefore the cross profile usually has a parabolic shape, the center line being 0.2-1.2\% thicker than the sides. Bending cylinders are used to apply a counteracting force on the work roll chocks to reduce the roll bending, thus controlling the cross profile partially.

In this article the improvement of the thickness control is discussed, focusing on the AGC system. 


\section{AGC Control Tasks}

The rolling accuracy mainly depends on the automated gauge control (AGC) performance. The main tasks of an AGC system include:

- Mill stretch compensation

- Lock-on gauge control

- Work roll thermal expansion compensation

- Oil film compensation of back-up roll bearings

- Work roll bending

- $\quad$ Tapering

- Roll eccentricity compensation

- Thickness feedback control

- Predictive and adaptive control methods

Due to the given application and requirements, not all of the above mentioned features need to be applied to achieve acceptable thickness performance. The proper selection and combination of the various control techniques vary according to the given process and the available measurements.

\subsection{Mill Stretch Compensation}

As the strip passes between the work rolls, the thickness is reduced. The rolling force depends on the thickness reduction, on the characteristics of the rolled material, on the friction conditions, and on further process variables as well as unknown disturbances. Since the rolling force loads the mill stand, the stand suffers elastic deformation, called the mill stretch, and without compensation it would cause significant deviation in the thickness of the output product.

The mill stretch force can be measured by load cells or calculated from the measured HGC pressure and can be used to calculate the mill stretch. The mill modulus has to be measured during the commissioning of the system.

Within the operating range, the elastic deformation of a mill stand can reach a couple of millimeters. The target thickness tolerance ranges from \pm 0.1 to $0.3 \mathrm{~mm}$, therefore the accurate measurement of the spring modulus is essential for the appropriate mill stretch compensation. The spring modulus can be considered constant, however, due to several mechanical components, there can be a slight nonlinearity in the low force range (Fig. 2).

On the unloaded mill there is no force before the slab or the strip arrives into the roll bite, therefore the gap has to be pre-set with an anticipated mill stretches. The anticipated mill stretch depends on the strip characteristics (size, material) and can be calculated using a high level system. 


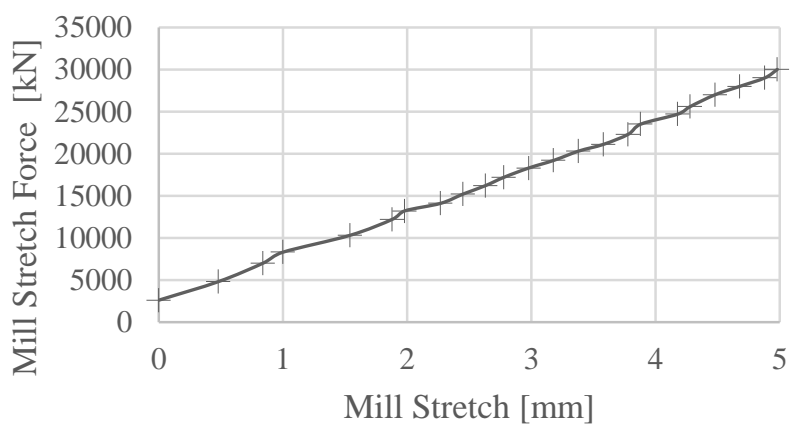

Figure 2

Measured mill stretch characteristic

When the mill is loaded, the mill stretch force is measured by load cells or calculated from the measured HGC pressure and can be used to calculate the actual mill stretch. A commonly used method is to take the elastic mill modulus into account and, using a feed forward error compensation, to compensate the mill stretch [3].

It is advised to filter the measurement errors or rapid force changes, because they cause sudden radical changes in the thickness of the output material.

Also, a proper safety protocol has to be added to the algorithm, since there is a positive feedback in the mill stand force control loop. If the force increases, the AGC closes the stand, which results in increasing force as well. If the stand works close to the maximum stand force, proper limiters have to be applied.

\subsection{Lock-on Type Gauge Control}

Under steady state rolling conditions, a linear relationship between the exit strip thickness, roll gap, and rolling force can be expressed by spring equation Eq. (1):

$h_{0}=S_{0}+\frac{F_{0}}{M}$

where $S_{0}$ is unloaded roll gap; $F_{0}$ is rolling force; $M$ is the mill stiffness or mill modulus.

The strip thickness reference has to be created first during the lock-on process by calculating the average values of the actual roll gap and the actual rolling force. According to the spring equation, the strip thickness reference is shown in Eq. (2), where $\mathrm{S}$ is locked roll gap; $\mathrm{F}$ is locked rolling force.

$$
h=S+\frac{F}{M}
$$


The thickness deviation $\Delta \mathrm{h}$ can be calculated as follows:

$\Delta h_{0}=h_{0}-h=S_{0}-S+\frac{F_{0}-F}{M}$

The reference roll gap to eliminate thickness deviation $(\Delta \mathrm{h}=0)$ is:

$$
\Delta S_{G M}=-\left(1+\frac{Q}{M}\right) \cdot \Delta h=-\left(1+\frac{Q}{M}\right) \cdot\left(S_{0}-S+\frac{F_{0}-F}{M}\right)
$$

where $\mathrm{Q}$ is the plastic modulus of the strip.

The structure of a commonly used AGC system, called the BISRA AGC, can be seen in Figure 3. The APC block represents the hydraulic servo, with the cylinders feedback and position controller.

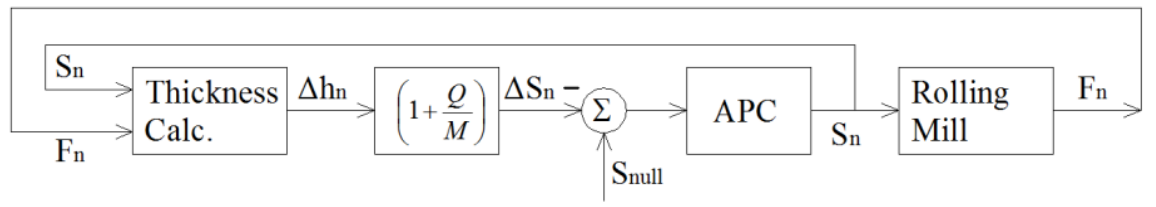

Figure 3

Schematic structure of the BISRA AGC

For accurate accurate calculations, it is first necessary to ensure that the spring curve is accurate. In most cases, linear approximation is sufficient. However, since the rolling mill has a complex mechanical structure, the ideal condition does not exist; the thickness deviation cannot be eliminated completely [2]. A good method to make the BISRA calculation more accurate is to measure the mill stretch under different pressures on an empty stand, pushing the work rolls together. This way the nonlinear mill modulus curve can be measured, and used for the calculation of mill stretch. Usually this measurement also requires some corrections, since the stand and the work rolls do not operate on working temperature in this case.

\subsection{Work Roll Thermal Expansion Compensation}

Work roll thermal expansion has a direct effect on strip thickness. Heat is generated in the strip due to deformation and conducted to the work roll when they are in contact. In addition, there is friction between the strip and the roll, which also generates heat. The work rolls are cooled by the emulsion, applied as lubrication between the rolls and the material.

Since direct measurement of the work roll's mean mass temperature is not possible, mathematical modelling can be used to estimate thermal expansion in working conditions. The measurement of the work roll surface temperature does not give the exact value of the mean-mass temperature, and this measurement is not practical, since emulsion is sprayed over the surface of the rolls [5]. 
Another way to determine the thermal expansion of the work roll is the modelling of the heat transfer between the work rolls and the strip. This depends on the roll speed, strip thickness, the properties of the strip, roll gap, contact time and cooling parameters. Most of researches focus on the thermal expansion contour of the work roll, and development of a proper coolant profile to compensate for the thermal expansion across the work roll [6].

From the aspect of the AGC, thermal expansion in the center line has to be calculated and compensated.

Without the above described mathematical modelling, operators manually adjust the gap to achieve the desired initial roll gap during threading.

\subsection{Oil Film Compensation of Back-up Roll Bearings}

In order to support the high rolling force, often friction bearings are applied as back-up roll bearings. In this type of bearing, an oil film separates the chock from the roll shaft. In a given bearing, the oil film thickness depends on the viscosity of the lubrication oil, the load and the rotational speed of the shaft (rolling speed), causing thickness variations. The most critical condition of the friction bearing, is the start-up under load, or operation at a very low speed.

To enhance the formation of the oil film at a low speed, hydrostatic lubrication systems can be applied. When hydrostatic lubrication is used, the oil film thickness $h_{f}$ can be calculated using Eq. 5 and can be adjusted during operation [7] (Fig. 4).

$h_{f}=\frac{a(V / F)}{(V / F)+b}$

Where, $V$ - roll speed, $F$ - roll force, $a, b$ - constants.

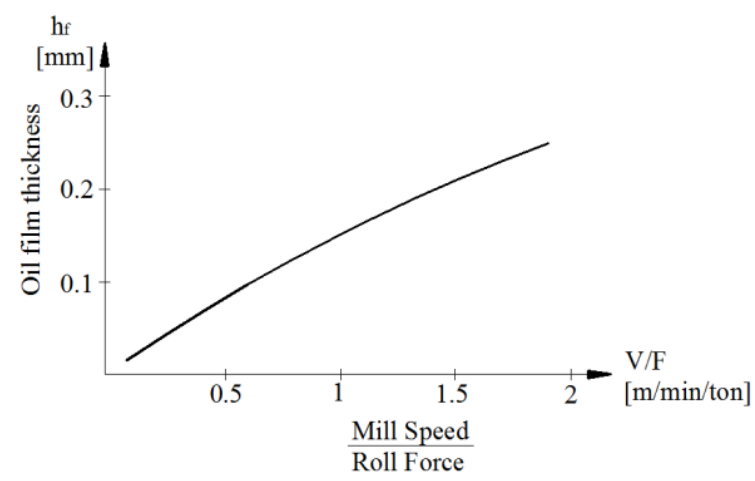

Figure 4

Relation between oil film thickness $h_{f}$ and ratio of roll speed $V$ to roll force $F$ [7] 


\subsection{Work Roll Bending}

Roll bending is not directly linked to thickness control, but usually this control is incorporated in the same hardware, together with AGC.

Work roll bending forces are applied, using hydraulic cylinders, to the work roll shafts located at both roll ends. As a simplified explanation, positive or crown-in bending is applied, when the bending forces open the roll gap. Crown-in bending causes the strip profile to be concave. Negative or crown-out bending is when the bending force closes the roll gap, and results in a convex profile (Fig. 5). The positive roll bending force influences the mill stretch force, but does not have any effect on the rolling force.

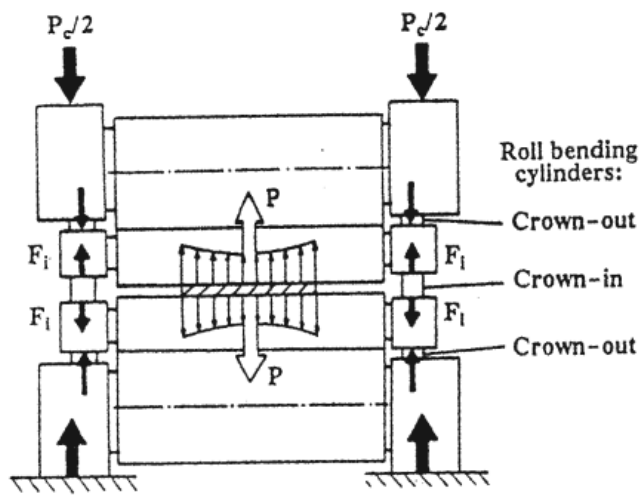

Figure 5

Work roll bending forces in 4-roll mills

\subsection{Tapering}

The hot rolled strip is later processed by a cold rolling mill, and to facilitate the threading operation, tapering is applied. Tapering is activated by a sensor which is located at a given distance from the mill stand on the rolling table at the entry side, and gives a signal when the strip end is in a given distance. This signal activates the tapering function, so the rolling thickness set-point is decreased following a given ramp.

\subsection{Roll Eccentricity Compensation}

Roll eccentricities are caused by axial deviation between the roll barrel and the roll shaft [4].

Roll eccentricity causes a periodic variation of the material thickness (Process Value PV), which can be measured with the thickness gauge (Fig. 6). This periodic disturbance is really hard to take out because of the dead time in thickness measurement. 


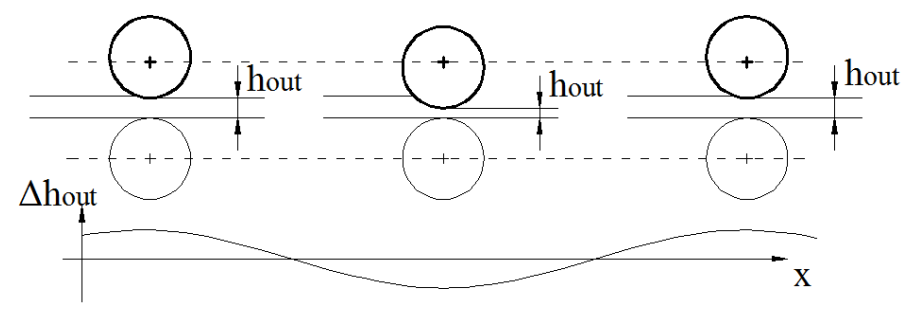

Figure 6

Effect of roll eccentricity on output strip thickness

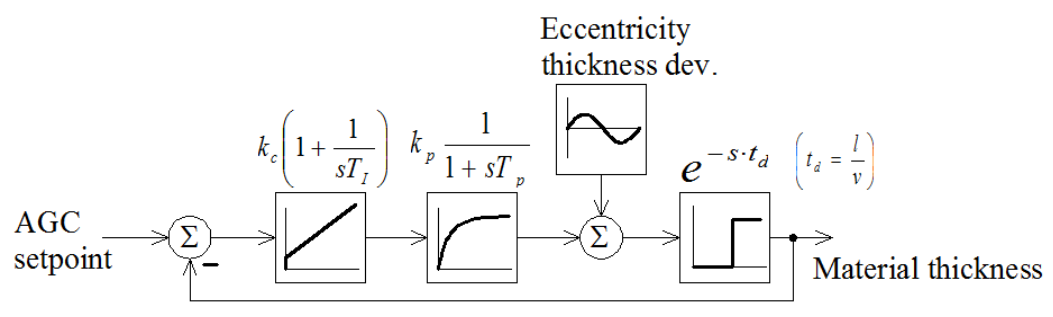

Figure 7

Thickness control loop with eccentricity thickness deviation as a disturbance

The hot rolling mill environment is quite harsh, so the X-ray thickness gauge is placed a few meters away from the roll gap. The dead time can be calculated from the distance between the work rolls and the thickness gauge (l), and the rolling speed $(\mathrm{v})\left(\mathrm{t}_{\mathrm{d}}=1 / \mathrm{v}\right)$. Considering approximately $2 \mathrm{~m} / \mathrm{s}$ rolling speed, the dead time can reach a few seconds. This amount of delay in a control loop makes accurate control difficult.

The aim of thickness control is to compensate for the slowly changing thickness deviations, using a PI controller. For this, the average of the measured thickness during one full rotation of the back-up roll is calculated and used as a process value for control. Because of the calculations and the long integration time, the control is slow, and the thickness deviation caused by eccentricity is not compensated.

The thickness deviation caused by the eccentricity has to be eliminated using other measurement and calculation methods than the X-ray thickness gauge. A possible solution is to make an eccentricity calibration measurement. After work roll change, eccentricity can be calculated on the unloaded mill, by rotating the touched work rolls (with a given force), and measuring the changing force that is loading the mill. The work roll shaft angle also has to be measured, and paired with the measured eccentricity.

Eccentricity can also be detected when the material rolls on the loaded stand, by detecting the periodic thickness deviation. The period time is known from the rotation speed (mill speed), measured by a shaft encoder or resolver. 


\section{Thickness Control}

A possible HGC control scheme can be seen on Figure 8. The above described disturbances which influence the thickness of the strip are taken into account by using them for feed-forward error compensation. So, if, e.g. the mill stand force increases during rolling, the mill stretch compensation acts immediately, not waiting for the feedback thickness controller.

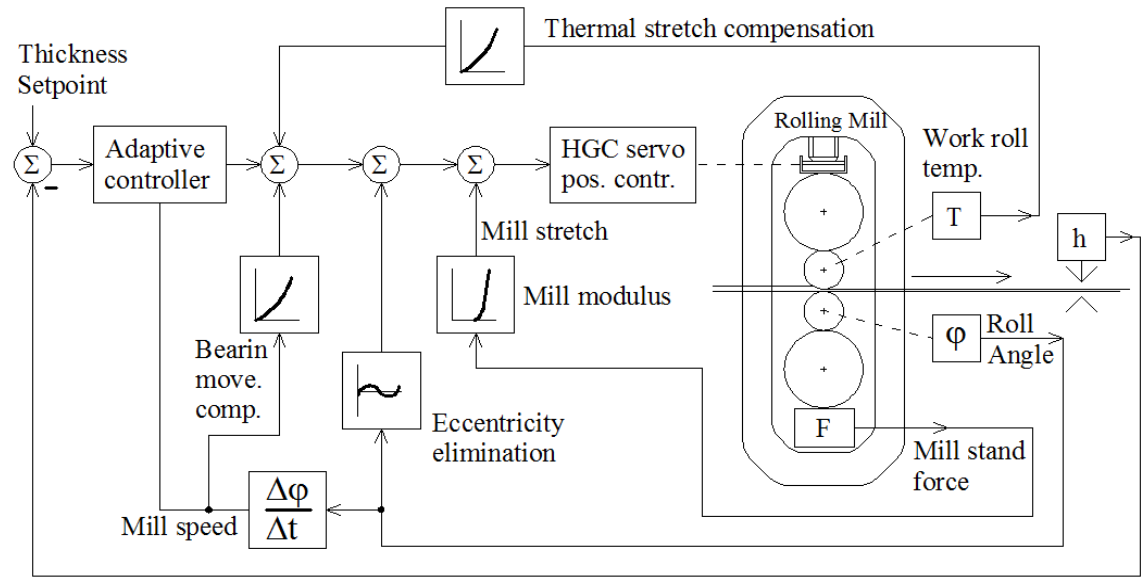

Figure 8

HGC control scheme

The simplest solution to achieve a thickness feedback control, is to choose a PI controller with dominating I effect, as it was mentioned before (Fig. 7). The rolling process can be modelled as a first order function with a delay (Eq. 6).

$G_{p}(s)=k_{p} \frac{1}{1+s T_{p}} \cdot e^{-s T_{d}}$

The controllability can be defined by the ratio of $T_{p}$ - process time constant to $T_{d}$ - dead-time. In case of a rolling mill $T_{p}$ is a few hundred milliseconds and $T_{d}$ is a few seconds; thus, the ratio shows a process which is really difficult to control. Popular recommendations are to use a pure I or PI controller (with dominating I) [8]. On Figure 9 a real measurement in a rolling mill is shown where during rolling the mill speed had to be decreased to about $30 \%$. (It is not typical to change the mill speed during rolling, but it can happen if there is some technical problem with the tension reel or the side cutter.) The dead-time has linear connection to the mill speed (Eq. 7).

$T_{d}=\frac{l}{v}$ 
Where $\mathrm{v}$ is mill speed and $\mathrm{l}$ is the distance between the work rolls and the X-ray thickness gauge. As the mill speed changes (about 150 seconds after the rolling starts), the control becomes unstable, and causes a periodic oscillation in the output thickness.
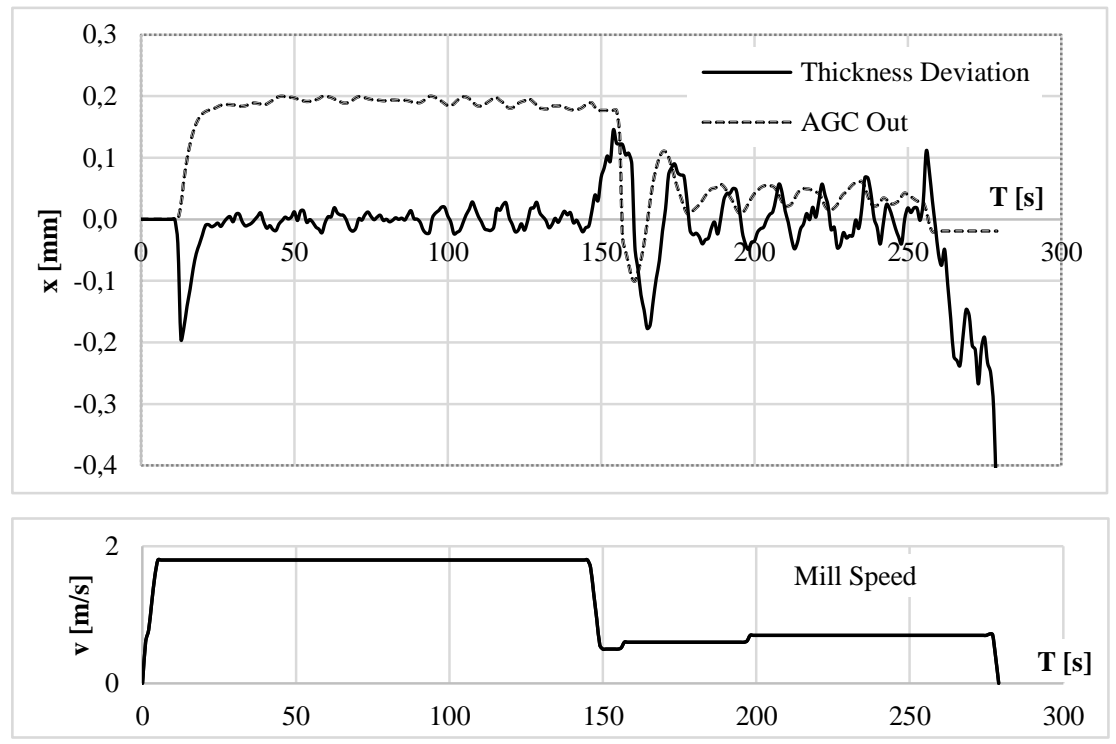

Figure 9

AGC control instability because of mill speed change

\subsection{Adaptive PI Controller}

A possible solution for the above mentioned problem is to use an adaptive PI controller, where the controller gain and the integration time are calculated by taking into consideration the mill speed.

A simple MATLAB simulation presents the structure of a possible adaptive PI controller (Fig. 10.). This simulation shows the advantages of using an adaptive controller instead of classical PI.

In the simulation the dead-time is set to 3 seconds, and after 30 seconds of rolling the speed is decreased to $1 / 3$ of the nominal process speed, which causes 3 times more dead-time. As the mill speed is reduced, the classical PI control becomes unstable. A disturbance in thickness is modelled by a derivative, which gives a pulse signal when the speed changes, and adds it to the process output. A simple practical formula is used to set the controller parameters (Eqs. 8, 9) [10]:

$k_{c}=\frac{0.3}{k_{p}}$ 


$$
T_{i}=0.42 \cdot T_{d}
$$

The process gain $\mathrm{kp}=1.5(\mathrm{~T} p=0.2 \mathrm{~s}$ ) was used (estimated from Fig. 8). So the transfer function of the controller is (Eq. 10):

$G_{c}(s)=0.2 \cdot\left(1+\frac{1}{0.42 \cdot T_{d} \cdot s}\right)$

In classic PI, Td is constant 3 seconds, in the adaptive PI, the calculated dead time is used to set the integrator parameters.

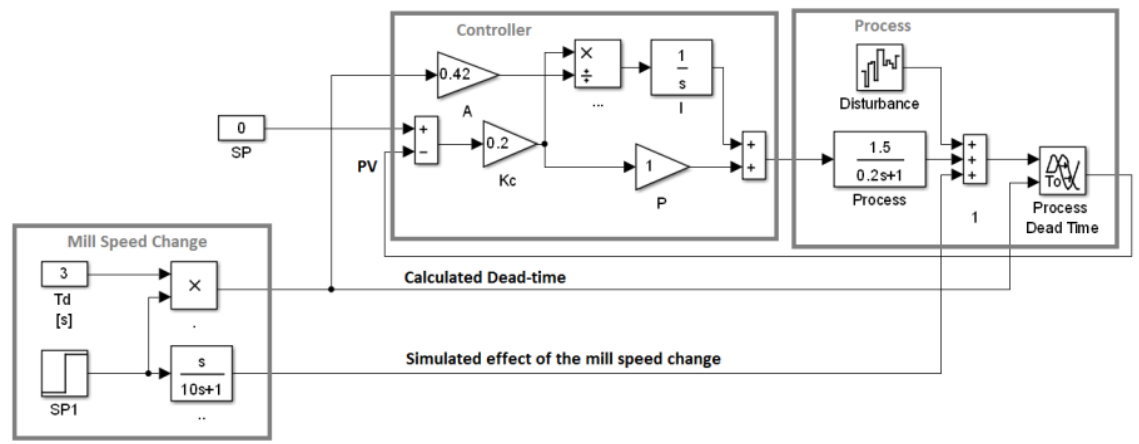

Figure 10

Structure of the adaptive PI thickness controller

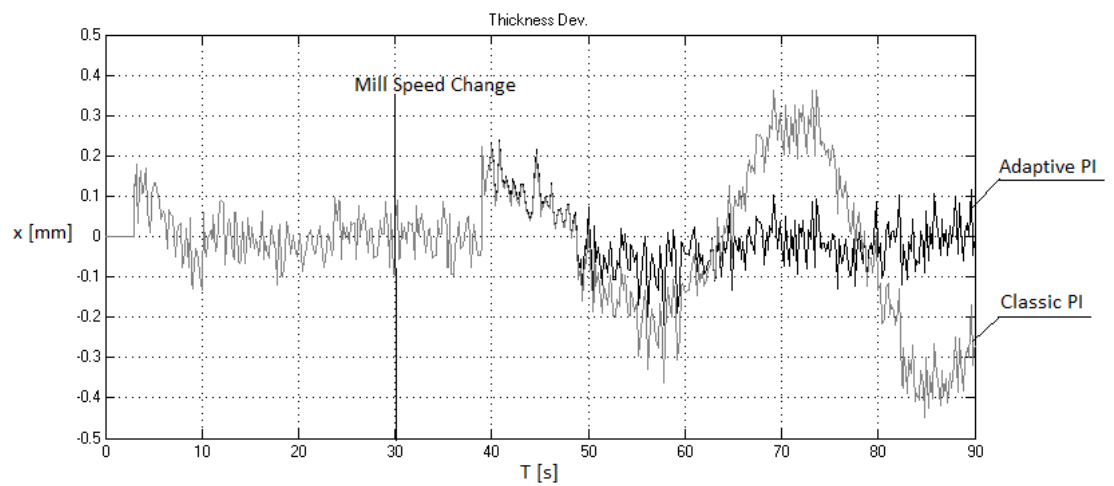

Figure 11

Comparison of the adaptive and the classic PI controller

As a result of the simulation the thickness deviation in time can be seen on Figure 11. As it could also be seen from the real measurements, the classic PI starts oscillating as the mill speed changes, but the adaptive one remains stable. 


\subsection{Predictive Controller}

In the case of rolling mills, predictive control is an option, to achieve improved performance. This is because the dead-time can be calculated from the available speed measurements. However, the development of a suitable process model is a challenge.

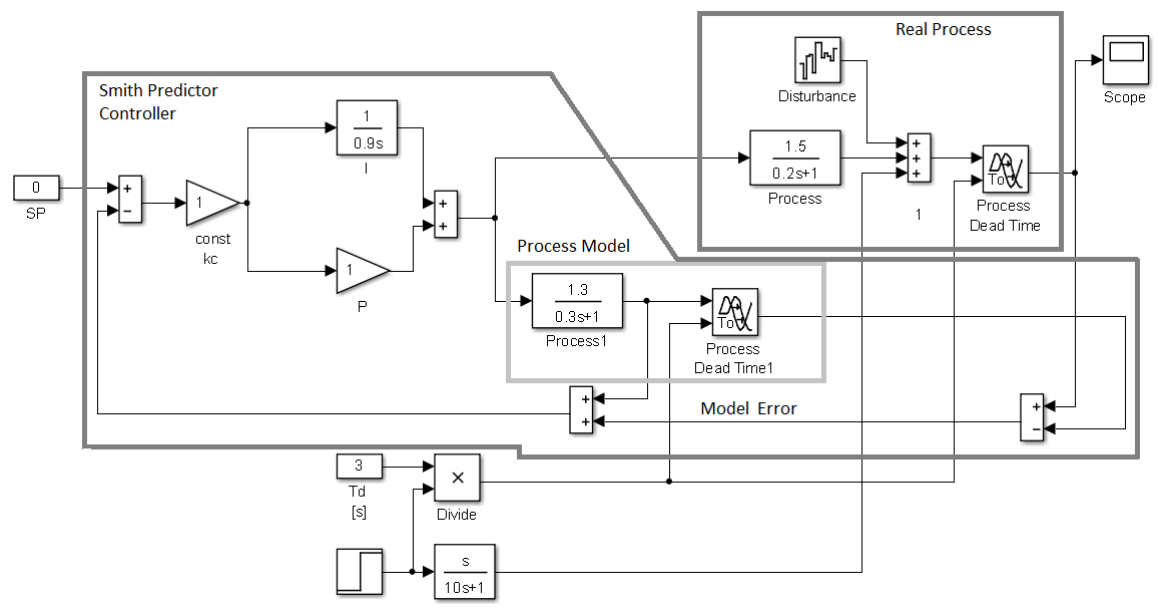

Figure 12

Structure of the Smith Predictor thickness controller

In Figure 12 a conventional Smith predictive controller MATLAB model can be seen. The PI controller output is connected to the process input, and also to the process model. The process model is divided into the first order and the dead-time parts, and the signal connecting these two blocks together is wired back to the PI controller as a simulated process value (without the dead-time). Also, the real process output and the model output are subtracted, giving the model error. If there is no model error, only the first order lag part of the model is "controlled" (without the dead-time), this way the controller can be tuned with high gains. The model error is added to the simulated process value and thus it is compensated [11].

The result of the simulation shows a better response, even if the model gain and the model first order lag time constant, were set intentionally to a different value from that of the real process to represent the effect of errors in the model. A step signal has been applied as a set point to compare the transient functions of the two controllers (Fig. 13). 


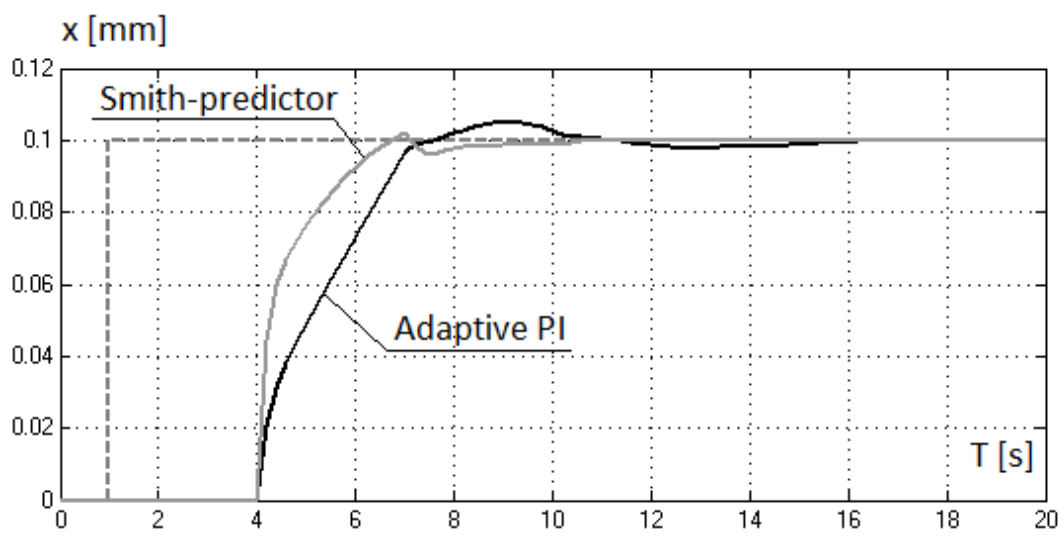

Figure 13

Comparison of adaptive PI and Smith-predictor controller transient function

\section{Improvement}

On Figure 14, the measured thickness deviation of a hot aluminum rolling mill can be seen, using a rolling speed-dependent adaptive PI thickness controller and mill stretch compensation.

The thickness deviation is within $\pm 0.06 \mathrm{~mm}$ range during the rolling process. The end of the rolled strip is cooled significantly by the coiler shaft, which causes a large thickness deviation error for the last few meters of the strip. This thickness error can be corrected by the downstream cold rolling passes.

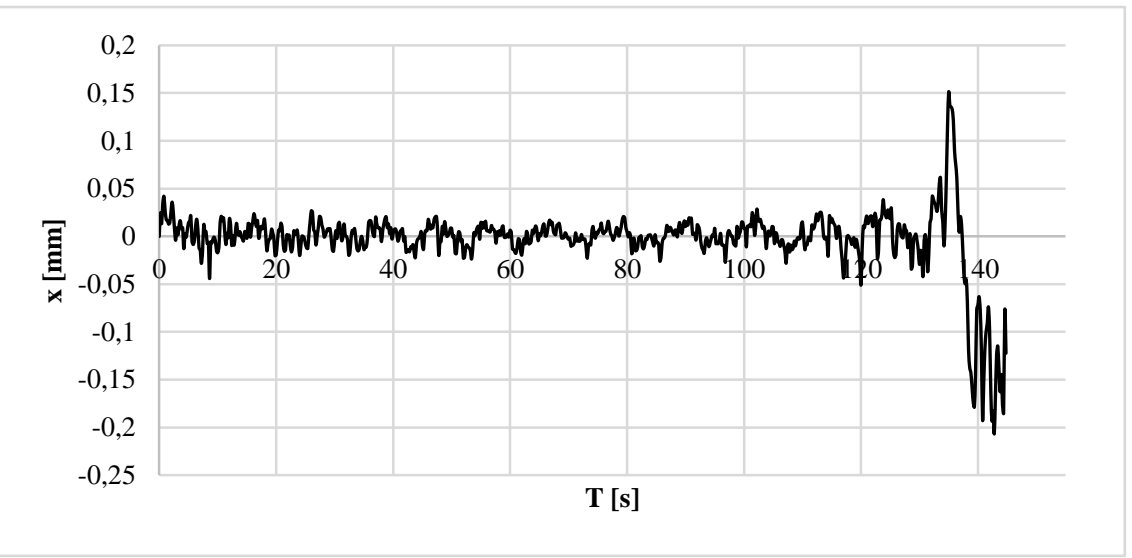

Figure 14

Measured thickness deviation using the adaptive PI controller and mill stretch compensation 


\section{Conclusions}

The structure of an existing AGC system has been analyzed and modified to introduce a thickness feedback control, within a hot rolling mill system. In order to avoid thickness oscillation at a reduced speed, a speed dependent adaptive PI regulator was applied. The improved system was validated by measurements.

In this paper, further improvement options are also analyzed, for example, eccentricity compensation and predictive control. These options promise further improvement possibilities.

\section{References}

[1] A. Jambor - L. J. Hubbard, Changing Product Structure and Comparative Advantage: the Case of Hungarian Agri-Food Trade. (2013, Ekonomicky Casopis 61:(8) pp. 846-860

[2] Degarmo, E. Paul; Black, J T.; Kohser, Ronald A., Materials and Processes in Manufacturing ( $9^{\text {th }}$ ed.) 2003 Wiley, ISBN 0-471-65653-4

[3] Ji Yafeng, Zhang Dianhua, Chen Shuzong, Sun Jie, LI Xu, Di Hongshuang, Algorithm Design and Application of Novel GMAGC based on Mill Stretch Characteristic Curve, Journal of Central South University March 2014, Volume 21, Issue 3, pp. 942-947

[4] Li Xua, Chen Shu-zonga, Du De-shunb, Chen Hua-xinc, Zhang Dian-huaa, Simulation and Analyzing on Model Parameters Effect of BISRA-AGC, 2011 International Conference on Physics Science and Technology (ICPST 2011), Volume 22, 2011, pp. 571-576

[5] Waleed I. Hameed, Khearia A. Mohamad, Strip Thickness Control of Cold Rolling Mill with Roll Eccentricity Compensation by Using Fuzzy Neural Network, Engineering, 2014, 6, pp. 27-33, ISSN Online 1947-394X

[6] I. Yu. Prikhod'ko, S. A. Vorobei, A. A. Sergeenko, V. V. Raznosilin, S. E. Shatokhin, Temperature Regulation of Rollers in Broad-Strip Hot-Rolling Mills, Steel in Translation, February 2011, Volume 40, Issue 11, pp. 985989, ISSN 0967_0912

[7] M. Abbaspour, A. Saboonchi, Work Roll Thermal Expansion Control in Hot Strip Mill, Applied Mathematical Modelling, Volume 32, Issue 12, December 2008, pp. 2652-2669

[8] NIIR Board of Consultants \& Engineers, The Complete Technology Book on Hot Rolling of Steel, National Institute of Industrial Research (2010) ISBN: 8190568582

[9] Ziegler, J. G.; Nichols, N. B. Optimum Settings for Automatic Controllers. Trans. ASME 1943, 65, 433

[10] J. Gerry, How to Control a Process with Long Dead Time, Control Engineering, 1998.03, ISSN 0010 8049, http://www.controleng.com/ 2015.03.25

[11] A. Vodencarevic, Design of PLC-based Smith Predictor for Controlling Processes with Long Dead Time, IMECS 2010, ISSN: 20780966 